
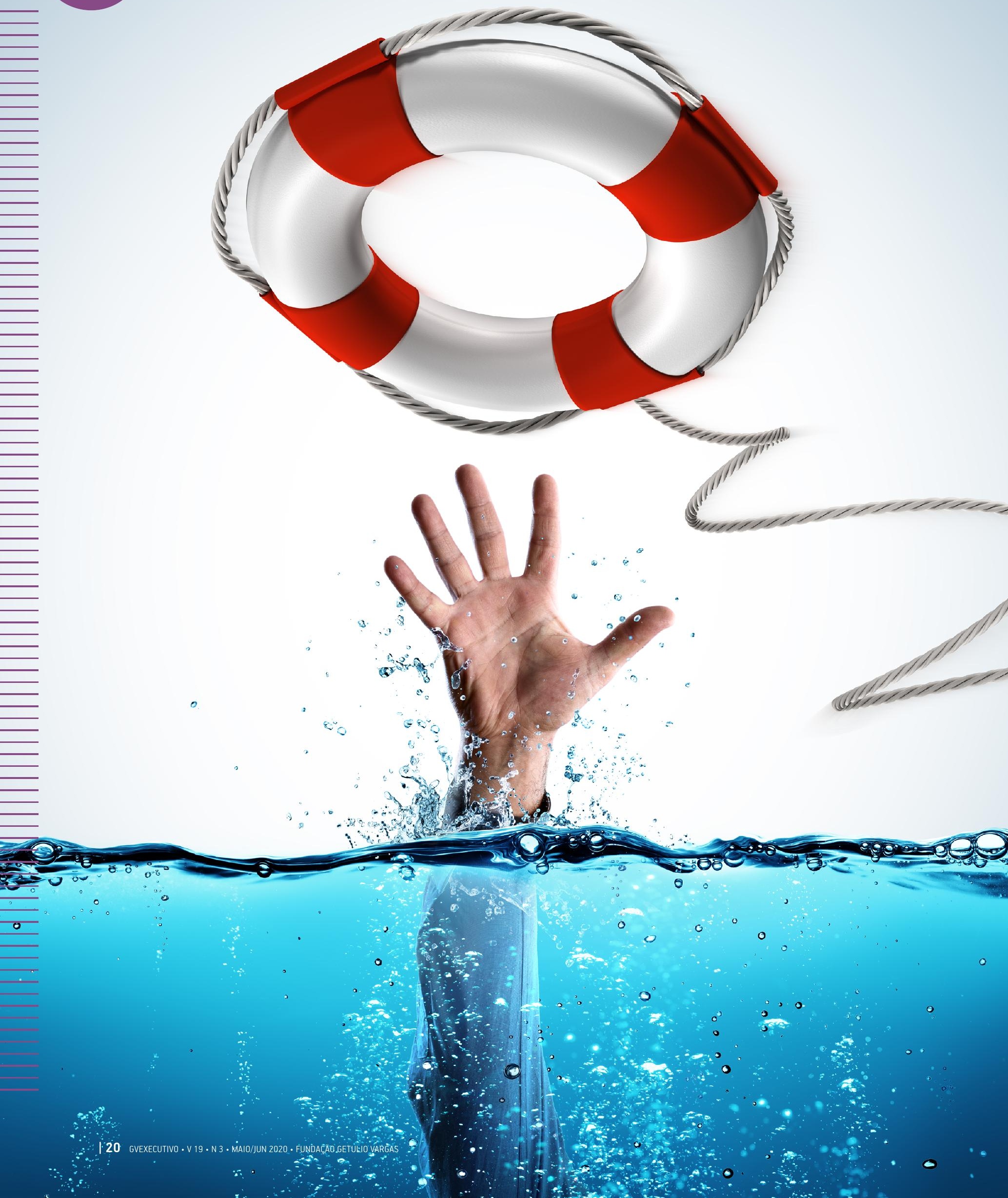

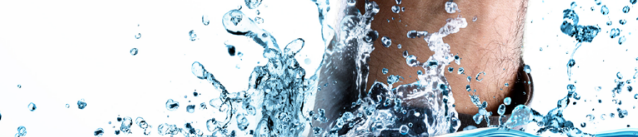




\section{ACHATANDO A CURVA DA INADIMPLÊNCIA}

| POR RAFAEL SCHIOZER E VALTER YOSHIDA JR.

\section{Como as medidas emergenciais para mitigar a crise econômica afetam o mercado de crédito tanto no curto quanto no longo prazo.}

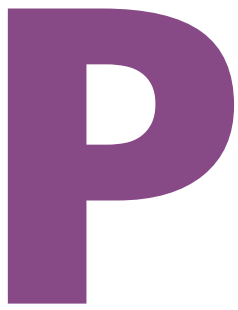

raticamente todos os países do mundo têm desenhado políticas econômicas para enfrentar a recessão derivada da pandemia da Covid-19. Um levantamento feito pelo Fundo Monetário Internacional (FMI) mostra que essas políticas incluem estímulos fiscais e monetários e vão do investimento emergencial no setor de saúde e programas de distribuição de renda à população vulnerável até a injeção de liquidez nos mercados financeiros e programas de crédito a empresas e indivíduos.

Este artigo procura lançar luz sobre as medidas que afetam o mercado de crédito no Brasil, com uma visão de médio e longo prazos, olhando para aspectos regulatórios, concorrenciais e tecnológicos.

\section{O APRENDIZADO DE OUTRAS CRISES}

Um conjunto enorme de estudos sobre crises econômicas, especialmente a de 2008, permite-nos ter hoje um diagnóstico muito útil a respeito dos mecanismos que ligam o mercado financeiro à economia real durante períodos de retração. Embora a crise que se inicia seja mais profunda e tenha origem diferente das anteriores, o aprendizado das crises anteriores ajuda na execução de políticas anticíclicas neste momento.

Um fenômeno bem documentado no Brasil e no mundo é a tendência dos bancos em diminuir a oferta de crédito diante de recessões. As medidas governamentais anticíclicas após a crise de 2008 tiveram sucesso em contrabalançar em parte esse processo. Por exemplo, o governo dos Estados Unidos assumiu o risco de operações de crédito num total de mais de 400 bilhões de dólares por meio do Troubled Asset Relief Program (TARP). Esse programa contribuiu para a estabilização do sistema financeiro, e os recursos investidos foram recuperados ao longo dos cinco anos seguintes, em grande medida porque parte do risco que estava embutido nos preços de uma parcela dos ativos não se materializou por completo, gerando lucro para o Tesouro.

No Brasil, os bancos privados diminuíram a concessão de crédito livre nos quatro trimestres que sucederam a falência do banco Lehman Brothers em 2008, como mostram Raquel Oliveira, Rafael Schiozer e Sérgio Leão em artigo de 2014. Em outro artigo, de 2016, Rafael Schiozer e Raquel Oliveira mostram que essa queda foi particularmente mais acentuada para as empresas pequenas (aquelas com até 50 funcionários). Ambos os trabalhos mostram que os bancos públicos assumiram um papel anticíclico, aumentando seus empréstimos no período. Na recessão brasileira de 2015 e 2016, as pequenas e médias empresas (PMEs) também foram as mais afetadas pelo corte de crédito.

Desde 2008, a regulação bancária foi aperfeiçoada. As modificações introduzidas exigiram dos bancos maior base de capital para suportar perdas. As novas regras também criaram mecanismos que permitem ao regulador requerer me- 


\section{CRÉDITO ÀS PMES E O EMPREGO NO BRASIL}

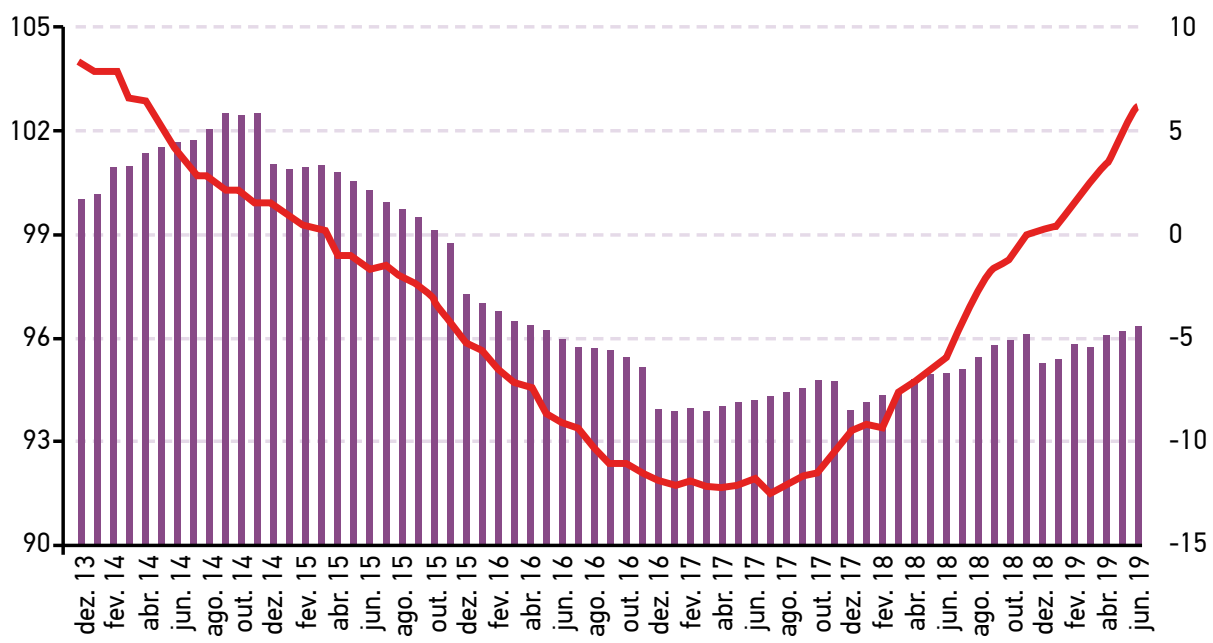

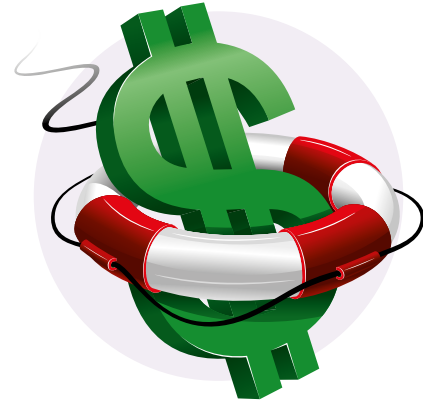

I Índice de emprego formal (base 100 em dez. 2013, eixo esquerdo).

- Variação em \% do crédito a PMEs (eixo direito). nos capital durante recessões, aumentando a capacidade de empréstimos dos bancos nesses períodos.

Aprendizados foram incorporados à regulação. Antes, em recessões, bancos eram incentivados a renegociar empréstimos com o intuito de diminuir artificialmente seus índices de inadimplência. No Japão, por exemplo, a repactuação sucessiva dos empréstimos desde a década de 1990 deu origem a um conjunto de empresas operacionalmente ineficientes (empresas zumbi), causando a má alocação dos recursos da economia e prolongando a recessão. A regulação pós-crise de 2008 passou a estabelecer critérios mais estritos para o provisionamento, que é o montante reservado para absorver perdas esperadas, de empréstimos renegociados. Com isso, criou incentivos para que os bancos renegociem apenas os financiamentos em que o tomador mostre real capacidade de pagamento, evitando os chamados empréstimos zumbi.

Em linha com o aprendizado das crises anteriores, as medidas tomadas no Brasil para combater a crise atual têm seis vertentes principais:

- Assunção de risco de crédito pelo governo (via Banco Nacional de Desenvolvimento Econômico e Social - BNDES, Banco Central do Brasil ou Tesouro Nacional) em algumas operações feitas por bancos privados;

- Aumento da participação dos bancos públicos na oferta de crédito;

- Criação do novo depósito a prazo com garantias especiais (NDPGE), para mitigar a ocorrência de corridas bancárias;
- Injeção de liquidez no sistema, com a redução dos depósitos compulsórios e outras medidas pontuais;

- Diminuição da exigência de capital dos bancos. Destaca-se aqui a redução do requerimento de capital de conservação dos bancos;

- Flexibilização da regulação sobre provisionamento de empréstimos repactuados.

As três últimas vertentes visam manter a capacidade dos bancos em ofertar crédito, diminuindo restrições de liquidez e de capital. A última é uma das medidas que terá mais impacto sobre o mercado de crédito, especialmente para as PMEs. Há grande preocupação com o crédito a essas empresas, que, conforme mostra o gráfico, tem relação direta com o nível de emprego no Brasil.

\section{O PAPEL DA RENEGOCIAÇÃO E A VOLTA À NORMALIDÁDE}

Estamos observando um volume de renegociação de empréstimos em escala nunca vista anteriormente no Brasil, de modo especial para pessoas físicas e PMEs. Segundo levantamento da Federação Brasileira de Bancos (Febraban), mais de dois milhões de tomadores já pediram a repactuação de seus financiamentos, em volume superior a $\mathrm{R} \$ 200$ bilhões. $\mathrm{Na}$ maioria dos casos, os empréstimos têm sido renegociados com carência de 60 dias para reinício dos pagamentos.

Essas condições dão um fôlego imediato às famílias e empresas que tiveram quedas drásticas de seus fluxos de cai- 
xa com a pandemia, mas possivelmente serão insuficientes para boa parte dos tomadores. Muitos empréstimos precisarão de novas reestruturações, de prazos ainda mais longos, fazendo com que algumas das empresas afetadas pela crise, mesmo aquelas estruturalmente saudáveis, levem anos para quitar suas dívidas.

Assim como o isolamento social visa achatar a curva de contágio pelo vírus, a renegociação de empréstimos procura evitar um pico de inadimplência. Em um momento em que é muito difícil avaliar o quanto aumentou o risco de cada empréstimo individualmente, faz sentido que bancos e tomadores renegociem o prazo de suas dívidas e que o regulador relaxe as exigências para que as renegociações aconteçam. Assim como reduzir o pico de infecção pelo vírus permite ao sistema de saúde salvar mais vidas, achatar a curva de inadimplência permite a sobrevivência de empresas e famílias estruturalmente saudáveis, mas com problemas financeiros de curto prazo.

Ao longo dos próximos meses e anos, caberá aos bancos avaliar quais empréstimos são viáveis para novas repactuações ou não. Esse pode ser um processo de alguns anos, pois a mudança de risco de crédito de empresas e famílias será afetada por uma série de fatores que não estão hoje nos modelos dos bancos. Além dos fatores macroeconômicos tradicionais (por exemplo, com que velocidade o produto interno bruto - PIB - e o emprego vão se recuperar), mudanças de comportamento pós-pandemia afetarão diferentemente as receitas dos diversos setores da economia.

O uso de novas tecnologias de ciências de dados pode auxiliar na identificação dos tomadores com real capacidade de pagamento (ou seja, distinguir tomadores com dificuldades conjunturais daqueles com problemas estruturais). Por exemplo, os bancos podem usar, na análise de crédito a pequenos e médios varejistas, dados de tráfego de pessoas nas lojas e de internautas nos canais virtuais de vendas.

Ao regulador, cabe avaliar com cuidado em que momento deve voltar a exigir dos bancos um maior provisionamento de operações repactuadas. A ideia é, por um lado, permitir a repactuação das dívidas de tomadores com situação financeira estruturalmente viável e, por outro, evitar a repetição da experiência japonesa dos empréstimos zumbi. Um processo gradual de normalização, ao longo de vários anos, parece ser o caminho mais sensato.

Olhando para além das renegociações, também é preciso ter cuidado ao avaliar o momento de desfazer as medidas anticrise. A experiência anterior mostra que a retirada das medidas extraordinárias deve ser um processo gradual ao longo de alguns anos, ponderando a velocidade de re- tomada da economia e a manutenção de um sistema financeiro saudável. As medidas de cunho regulatório (capital e liquidez) podem ser revertidas mais lentamente. Já aquelas com impacto fiscal talvez tenham de ser retiradas mais rapidamente, uma vez que a situação fiscal brasileira não permite a continuidade de estímulos desse gênero por períodos longos.

\section{OLHANDO PARA O FUTURO}

Você já deve ter escutado a frase: “Após a pandemia, o mundo não será o mesmo de antes". Essa afirmação provavelmente se aplique também ao mercado de crédito. Embora prever o futuro seja difícil nesse cenário, fazemos um exercício para auxiliar gestores e reguladores em suas tarefas de definir estratégias para o futuro.

A gestão da carteira de crédito às PMEs, os empréstimos visando à manutenção do emprego nessas empresas $\mathrm{e}$ a condução das novas rodadas de renegociação das dívidas terão papel fundamental no desenho do mercado de crédito e na lucratividade dos bancos nos próximos anos. Nesse sentido, a crise pode acelerar o uso de tecnologia nos processos dos bancos. Aqueles que o fizerem de maneira mais eficiente terão vantagem competitiva, o que pode até mesmo mudar o desenho concorrencial do mercado.

As modificações no panorama de crédito vêm acompanhadas de alguns riscos. Mesmo com todas as medidas de mitigação adotadas pelo governo, teremos um cenário de maior inadimplência em 2020 e 2021 do que nos dois anos anteriores. Segundo relatório recente do Credit Suisse, a inadimplência de empréstimos a PMEs até 2021 deve ser de 5 a $7 \%$ no sistema financeiro, nível similar ao atingido após a recessão de 2015 e 2016. Se essas previsões se confirmarem, teremos um cenário difícil, mas gerenciável. No entanto, se o baque sobre o produto e o emprego for mais forte do que o esperado, poderemos ter índices de inadimplência ainda superiores. Finalmente, o relaxamento das exigências de provisões sobre empréstimos renegociados pode dar origem a índices de inadimplência que não são comparáveis aos de períodos passados.

\footnotetext{
PARA SABER MAIS:

Raquel Oliveira, Rafael Schiozer e Sérgio Leão. Atuação de bancos estrangeiros no Brasil: mercados de crédito e derivativos de 2005 a 2011. Revista de Administração Mackenzie, v.15. n.2, 2014. Disponivel em: https://doi.org/10.1590/S1678-69712014000200007 Rafael Schiozer e Raquel Oliveira. Asymmetric transmission of a bank liquidity shock. Journal of Financial Stability, v.25, 2016. Disponivel em: https://doi.org/10.1016/j.j5.2015.11.005

RAFAEL SCHIOZER > Professor da FGV EAESP > rafael.schiozer@fgv.br VALTER YOSHIDA JR. > Doutorando na FGV EAESP e analista do Banco Central do Brasil > valter.yoshida@gvmail.br

*As opiniões expressas neste trabalho são exclusivamente dos autores e não refletem, necessariamente, a visão do Banco Central do Brasil.
} 